\title{
EL PRINCIPIO DE CONFIANZA LEGÍTIMA COMO FUNDAMENTO DE LA RESPONSABILIDAD PATRIMONIAL DEL ESTADO LEGISLADOR EN EL ORDENAMIENTO JURÍDICO ESPAÑOL
}

\author{
Óscar M. Reina García \\ Máster en Derecho Público, Universidad Carlos III de Madrid, España; Especialista \\ en Derecho Administrativo, Universidad Externado de Colombia; \\ Abogado Universidad Santo Tomás - Seccional Bucaramanga (Col). \\ Asesor jurídico Alcaldia Municipal Barrancabermeja (Col) \\ E-mail: mauricioreinag@hotmail.com
}

\begin{abstract}
Resumen
El Estado estructura su organización política, económica y social a través de la expedición de leyes, las cuales en algunas ocasiones varían las situaciones jurídicas que inicialmente protegían, y de esta manera generan inseguridad a los sujetos a quienes se les aplican las mismas, y que confiaban legítimamente en la permanencia de la norma. En el presente trabajo, se analiza la posibilidad de endilgarle responsabilidad al Estado por su actividad legislativa, cuando la aplicación directa de una norma lesiona intereses patrimoniales, en contravía del principio de seguridad jurídica y el de confianza legítima.

El anterior estudio lleva de manera inevitable a reflexionar si es posible establecer límites confianza legítima- al poder de innovación legislativa del Estado, toda vez que al pretender que se aplique un régimen de responsabilidad patrimonial al poder público legislativo, no se hace otra cosa que circunscribir unas de las principales funciones del Estado. Las posiciones frente a este tema y los argumentos que las soportan se tratan de reflejar en el presente escrito, con el ánimo de efectuar un análisis integral en el ordenamiento jurídico español, que permita concluir que todas las actividades del poder público, incluso la legislativa, en un modelo de estado social de derecho se encuentran limitadas.
\end{abstract}

\section{Palabras claves}

Confianza legítima, Estado legislador, seguridad jurídica, medidas transitorias, reparación de perjuicios, innovación legislativa y responsabilidad patrimonial

\begin{abstract}
The State structures its political, economic and social systems through the expeditions of aws, which in some occasions may change legal situations that they previously regulated in a different way. This change generates legal insecurity on the subjects to whom the laws were changed, and who legally expected the law to maintain their legal conditions. In present work, it will be analyzed the possibility to claim responsibility from the State due to is legislative activity, when the direct application of a norm affects patrimonial interests in oppose to the principle of legal security and legitimate trust.

The previous study leads without a question to think about the possibility to establish limits - legitimate trust - against the State legislative power, since to pretend to apply a patrimonial responsibility regime to the public legislative power is not different to circumscribe on of the main powers of the State. The positions about this topic and the arguments that supports them are reflected in this work, with the hope to perform an integral analysis to the Spanish legal system, that allows us to conclude that all activities of the public power, even the legislative, are limited within the model of the social
\end{abstract}

\section{Key Words}

Legitimate trust, legislative State, legal security, transitory measures, punitive damages, legislative innovation and patrimonial responsability 

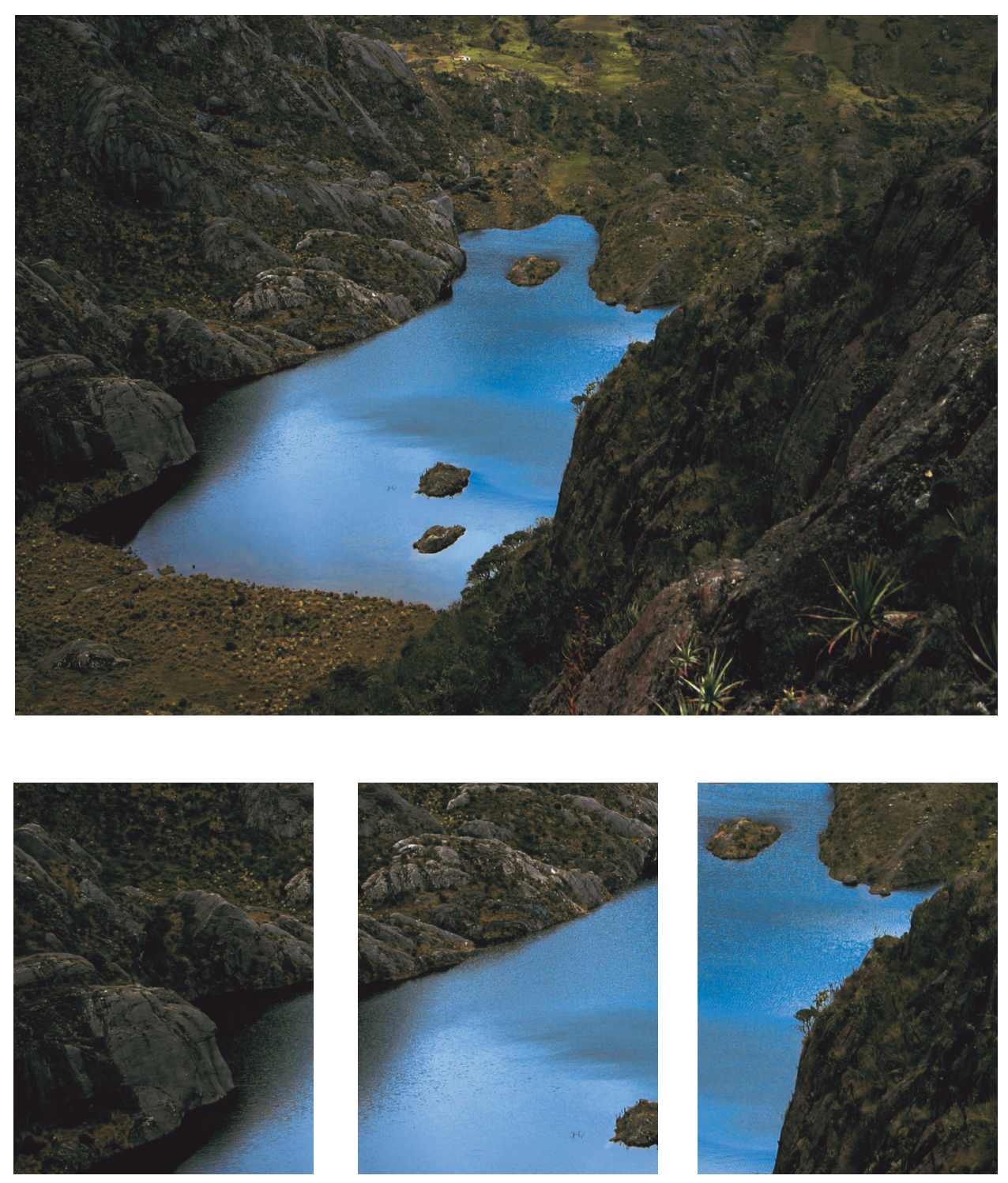

Laguna de "Las calles" 


\section{EL PRINCIPIO DE CONFIANZA LEGÍTIMA COMO FUNDAMENTO DE LA RESPONSABILIDAD PATRIMONIAL DEL ESTADO LEGISLADOR EN EL ORDENAMIENTO JURÍDICO ESPAÑOL*}

Óscar M. Reina García

\section{Introducción}

La actividad legislativa, una de las funciones esenciales del Estado social de derecho se ha incrementado ${ }^{1}$, debido a la necesidad de regular las relaciones sociales en un sistema jurídico cuya interdependencia con el modelo económico capitalista, lo lleva hacia un cambio constante $\mathrm{y}$, a su vez, lo obliga a buscar la adaptación legislativa que brinde un marco jurídico a las operaciones comerciales ${ }^{2}$. Esta situación en ordenamientos jurídicos como el español, se acelera aún más, puesto que su normatividad no sólo se sujeta a la actividad legislativa estatal, sino que también se encuentra condicionada a la producción normativa proveniente de la Unión Europea.

\footnotetext{
El artículo reflexiona sobre los límites -confianza legítima- en el Estado, en la aplicación de un régimen de responsabilidad patrimonial al poder público legislativo. El trabajo se desarrollo en el marco del Máster en Derecho Público desarrollado por el autor, Universidad Carlos III de Madrid, España.

1 En palabras de Botero Aristizabal actualmente el sistema jurídico padece de una hiperinflación e improvisación legislativa, en la cual el principio de confianza legítima juega un papel destacado. Cfr. BOTERO ARISTIZÁBAL, L.F. Responsabilidad Patrimonial del legislador. p. 279. Editorial Legis, 2007.

2 Sobre el particular Vaquer Caballería ha expresado "Frente a la aceleración del cambio social y económico, en segundo lugar, la reacción del Derecho demanda su rapidez de respuesta, para lo que incorpora en su acervo el valor de la celeridad (la que precise la eficacia en el ejercicio del poder público) y el cambio (pues ordenar la realidad implica adaptarla a la norma, que es ejercicio de una potestas variandi). VAQUER CABALLERÍA, M. La aplicación del ordenamiento jurídico en el espacio y el tiempo.
} 
Ahora bien, a este incremento en la elaboración de las normas jurídicas debe apuntársele, a su vez, una nueva concepción de la vigencia de las mismas, la cual deja atrás aquella regla general que propendía por la vigencia indefinida de la ley $^{3}$, y que ahora permite la existencia de normas de carácter transitorio, lo cual genera como consecuencia que las situaciones jurídicas que son reguladas por este tipo de normas se enfrenten a cambios permanentes que no generan estabilidad, ni confianza a los sujetos a los que se le aplican tales normas.

Así pues, este panorama legislativo en constante modificación, puede ocasionar en algunos casos que las situaciones jurídicas que regula, tengan una duración efímera en detrimento de los intereses patrimoniales de las personas que conforman el sistema económico y jurídico, quienes al verse sorprendidos por el cambio normativo intentarán buscar que les sea restablecida la situación en la cual inicialmente se encontraban, por cuanto que confiaban legítimamente en la permanencia de la misma.

Estos dos aspectos innovación legislativa y confianza legítima, delimitan el objeto de estudio a desarrollar en este escrito y que corresponde a la posibilidad de imputarle responsabilidad patrimonial al Estado legislador cuando al proferir una ley desconoce en forma directa - es decir, sin que sea necesaria la expedición de un acto administrativo de aplicación del acto legislativo- el principio de confianza legítima en el ordenamiento jurídico español. La investigación de este tema implica el análisis, así sea mínimo, de dos de los pilares sobre los cuales se cimienta el modelo democrático actual, soberanía y voluntad general.

La pertinencia de este estudio radica en la posibilidad de someter a revisión el ejercicio de la actividad legislativa, análisis que puede llevar, a su vez, a la revisión de la posible colisión entre el principio de legalidad y el de seguridad jurídica, y entre los intereses generales y los de los particulares que puedan verse afectados. Dada la importancia de los principios que se enfrentan es posible encontrar posiciones doctrinales opuestas, las cuales tratarán de reflejarse en este escrito.

Para llevar a cabo la presente investigación se analizará en primer lugar el fundamento constitucional de la responsabilidad patrimonial del Estado legislador y, a su vez, se reflexionará sobre la jerarquía que ocupa el principio de confianza legítima en el sistema normativo. En segundo lugar se comentarán los principales rasgos del principio de confianza frente a la responsabilidad patrimonial del Estado legislador, para lo cual se situará el debate en los temas correspondientes a la variación de la ley en el tiempo y la previsibilidad de la misma, los intereses patrimoniales que se pueden ver afectados por los cambios normativos y la forma de reparar los perjuicios en el evento de considerarse viable la responsabilidad patrimonial.

3 Sobre el particular puede consultarse en forma amplia el prólogo de Luciano Parejo Alfonso sobre la obra de Federico Castillo Blanco, en, CASTILLO BLANCO, F. La protección de confianza en el derecho administrativo, pp. 12 y 13. Editorial Marcial Pons, 1998. 
Finalmente este trabajo se dirigirá a examinar el tema de la competencia del Juez contencioso administrativo, para el reconocimiento de la responsabilidad patrimonial del Estado legislador derivada de la aplicación del principio de confianza legítima.

Antes de abordar el tema central de esta investigación, resulta necesario efectuar unas breves precisiones del origen, concepto y requisitos para que se configure el principio de confianza legítima con el fin de precisar el ámbito de aplicación del mismo. El origen de este principio se encuentra en el derecho administrativo alemán ${ }^{4}$, y tiene su fundamento según lo manifiesta García Luengo

"El principio de protección de la confianza tal y como ha sido elaborado en la jurisprudencia del BVergw $G$ se basa en la consideración de que aquellos que han confiado en la legalidad de un acto administrativo, no deben quedar en una situación peor, que la que gozarían si el acto administrativo no hubiese sido dictado" $"$

Posteriormente sería adoptado por el Tribunal de Justicia de la Comunidad Europea $^{6}$, y de allí pasaría por vía jurisprudencial al derecho español, reconocido en la STS 1989/1458, al resolver un caso en el cual la dirección general de personal y servicios del Ministerio de Educación y ciencia expide un acto administrativo que deniega la entrega de una subvención escolar al propietario de un colegio, bajo el argumento de no reunir los requisitos exigidos por la normativa pertinente, a pesar que en años anteriores le había sido entregada dicha prestación, motivo por el cual a

4 Fue reconocido, por vez primera, en la sentencia de fecha 14 de noviembre de 1956, emitida por el Tribunal Contencioso Administrativo Alemán, el caso que dio origen al fallo corresponde a una viuda de un funcionario que vivía en la República Democrática Alemana, a quien la administración le manifestó que si cambiaba su residencia a Berlín oeste le sería reconocida la pensión de viudedad, la viuda aceptó el cambio de su residencia y se le empezó a pagar su prestación, sin embargo, la administración constató posteriormente que esta persona no reunía los requisitos para acceder a la pensión, motivo por el cual se le exigió que devolviera las mesadas pensionales, a lo cual se opuso la viuda la cual demandó con fundamento en la confianza de lo que se le había prometido, el tribunal aceptó el argumento de la demandante porque consideró que en el primer acto administrativo se le prometía el reconocimiento de la pensión, y además se le hizo incurrir en gastos para mudar su domicilio. Cfr. GARCÍA MACHO, R. Contenido y Límites del Principio de Confianza Legítima: Estudio Sistemático En la Jurisprudencia del Tribunal de Justicia. En Revista española de derecho administrativo. pp. 561,562. En este mismo sentido precisa Lorenzo de Membiela que si bien para algunos autores el origen del principio se encuentra en el derecho alemán, para otros se halla en el código de procedimiento administrativo de la República Popular de Polonia de 14 de Junio de 1960. Cfr. LORENZO DE MEMBIELA, J.B. El Principio de Confianza Legítima como Criterio Ponderativo de la Actualidad Discrecional de la Administración Pública, en Revista de Administración Pública, p. 250, No 171 (2006).

5 GARCÍA LUENGO, J. El Principio de Protección de la Confianza en el Derecho Administrativo, p. 387, pie de página 88. Editorial Civitas, 2002.

6 Recuerda Sanz Rubiales que si bien el TJCE utiliza la confianza en la STJCE de 13 de Junio de 1965 (as. 111/63, Lemmerz Werke), sólo lo reconoce como principio en la STCJE de 5 de junio de 1973, as. 81/72, Comisión c. Consejo. Cfr. SANZ RUBIALES, I. El Principio de Confianza Legítima, Limitador del Poder Normativo Comunitario, en Revista de Derecho Comunitario Europeo, p. 96, No. 7, enero-junio de 2000. 
juicio del Tribunal Supremo se desconoce la confianza del administrado, el cual de buena fe confiaba en que la subvención se le entregaría nuevamente ${ }^{7}$.

Después de la sentencia referida el principio sería acogido en los fallos del Tribunal Supremo ${ }^{8}$. Por otro lado el Consejo de Estado ha tratado de delimitar el ámbito de configuración de este concepto señalando que

"cuando el proceder de la administración genera una apariencia y, confiando en ella, el ciudadano, de buena fe ajusta su conducta a esa apariencia, pesa sobre la administración la obligación de no defraudar esa confianza, y de estar a las consecuencias de la apariencia por ella creada"

Luego de su adaptación jurisprudencial, el principio de confianza legítima sería incorporado por vía legislativa a través de la ley 4 de 1999 artículo 1º, modificatorio de la ley 30 de 1992 artículo $3^{\circ}$.

El principio de confianza legítima ha sido considerado como una manifestación específica del principio de seguridad jurídica ${ }^{10} \mathrm{y}$, a su vez, su aplicación comporta un enfrentamiento frente al principio de legalidad. Si se toma a modo ejemplo el citado caso de las subvenciones se pueden identificar los dos extremos, por un lado la inicial decisión de la administración de reconocer la prestación económica al propietario del colegio, el cual confió en que en los años posteriores la situación seguiría la misma -recibiría la subvención-, este extremo se identifica con la

$7 \quad$ En la Sentencia del Tribunal Supremo -STS- citada Fundamento Jurídico - en adelante F.J.- 2, el Tribunal Manifestó "Con el acto denegatorio de la subvención solicitada se quebrantó la $<<$ fides $>>$ o confianza del administrado que ejercita una actividad de interés social y que para él una gravosa tarea en la creencia de que también sería subvencionado en el segundo periodo, como ya lo había sido en el primero; lo que supone que con tal actividad y conducta inicial de la administración para el primer período del curso 1983-1984, aceptada por el señor M.G., se estableció un vínculo jurídico contractual perfeccionado por el mero consentimiento y que desde entonces obligaba no sólo al cumplimiento del mismo, sino también a todas la consecuencias, que según su naturaleza eran conformes a la buena fe, al uso y a la ley-artículo 1258 del vigente Código Civil-; por lo que es conforme a la buena fe y al uso estimar que el abono de una subvención parcial en el primer período del mismo curso, supone el de la siguiente dentro de igual año académico siempre y cuando los supuestos fácticos no hayan cambiado, pues de buena fe fue inducido el señor M. G. por los actos indicados de la Administración a desarrollar una actividad educativa en la Formación Profesional de Primer Grado, aceptando unas consecuencias y esperando una postura administrativa indicada y anunciada con toda claridad por los actos propios de la administración;(...)."

8 Vale la pena destacar las siguientes Sentencias: STS 1990/1258, STS 1990/5180, STS 1997/1147, STS $1994 / 621$, STS $1996 / 6202$, STS 1991/2669, STS 1996/3373, STS 1995/5024, STS 2000/2112, STS 1998/2491, STS 1998/1677, STS 2000/1376, STS 1999 1839, STS 1998/7625, STS 2000/1615, STS 2000/1551, STS 1999/0629, STS 1998/4150, STS 1998/5667, STS 1999/3979, STS 1999/9298, STS 1998/1103.

9 Dictamen de 30 de mayo de 1996.

10 En la STS 1992/5312 el Tribunal Supremo manifestó que "Ninguna prueba se ha practicado en estos autos que pudiera coincidir a diferente solución, siendo por otra parte de recordar el principio de seguridad jurídica - art. 9. ${ }^{\circ}, 3$ de la Constitución- que reclama una protección de la $<<$ confianza de los ciudadanos en que sus pretensiones van a ser resueltas de modo igual para todos, sin discriminaciones injustificadas $>>$ ". 
confianza del administrado soportada en el principio de seguridad jurídica. Por otro lado, la segunda decisión de la administración de no renovar la subvención debido al incumplimiento de la normativa correspondiente, este extremo que se identifica con el principio de legalidad. Así pues, frente a esta colisión entre los dos principios, el juez ha de escoger a cuál le da aplicación de acuerdo a las circunstancias del caso concreto.

A continuación se enunciarán los requisitos para que pueda configurarse el principio de confianza legítima, se seguirá en este aspecto la clasificación que ha elaborado el profesor González Pérez ${ }^{11}$, la cual parte de los pronunciamientos del Tribunal Supremo para determinar los requisitos en mención.

El primer requisito es la existencia de un acto de la administración lo suficientemente concluyente como para provocar en el afectado una confianza que le permita creer que la administración actúa correctamente, a su vez, que él considere que su actuar es lícito y, por lo tanto, crea que sus expectativas frente a la administración son razonables. El segundo hace relación a la realización de actos o signos externos de la administración que orienten al ciudadano hacia una determinada conducta. El tercero consiste en que la actuación de la administración constituya una situación jurídica en la cual el ciudadano podía confiar.

El cuarto requisito corresponde a la presencia de una causa idónea que provoque la confianza en el administrado, es decir, que no sea producto de negligencia, ignorancia o mera tolerancia de la administración. El quinto hace alusión al cumplimiento de los deberes del caso concreto por parte del interesado, y finalmente que el desconocimiento de la confianza le genere al afectado unos perjuicios que no debe soportar ${ }^{12}$.

Una vez efectuado este breve enfoque del principio de confianza legítima, se estudiará a continuación lo correspondiente al núcleo de esta investigación.

\section{EI Fundamento Constitucional}

El análisis de la responsabilidad patrimonial del Estado legislador exige como primer paso verificar el soporte constitucional que pueda dar lugar a la misma, toda vez que pretendiendo radicar en cabeza del poder legislativo obligaciones derivadas de su actuar, deben encontrarse las normas constitucionales que en primer lugar estimen procedente la responsabilidad del Estado por el ejercicio de la actividad referida y, que en segundo lugar, tratándose de la supuesta responsabilidad por la vulneración específica de un principio como es el de confianza legítima, se establezca si tal principio goza de jerarquía constitucional y, por lo tanto, su desconocimiento dé paso al reconocimiento de la responsabilidad patrimonial.

11 GONZÁlEZ PÉREZ, J. y Otros. Comentarios a la ley 4/1999, de 13 de enero, de modificación de la ley 30 de 1992. p. 90, Ed. Civitas, 1999.

12 Ídem, pp. 90 a 96. 


\subsection{El soporte constitucional de la responsabilidad patrimonial del Estado legislador y la voluntad del legislador}

En el articulado de la Constitución española no se encuentra una norma específica que señale la procedencia de la responsabilidad patrimonial derivada de la actuación legislativa, de este argumento se valen quienes consideran que así como la norma superior estableció en su artículos 106.2 y 121, la responsabilidad patrimonial de la administración y la de la administración de justicia, respectivamente, así también debe existir una norma que haga lo propio con la supuesta responsabilidad patrimonial del Estado legislador ${ }^{13}$.

En apoyo de este criterio se ha pronunciado el Tribunal Supremo al manifestar que

"Pues bien, si la exigencia de responsabilidad por actuaciones de la Administración o de órganos de la Administración de Justicia, aunque objeto de un tratamiento más completo en los arts. 106.2 y 121 de la Constitución, los mismos se remiten y, por tanto, hacen necesario un previo desarrollo legislativo de la posible responsabilidad derivada de actos de aplicación de leyes, que hasta ahora cuentan únicamente con el enunciado genérico del art. 9.3 del texto constitucional, la necesidad de un previo desarrollo legislativo que determine en qué casos procede y qué requisitos son exigibles parece más indispensable en este caso, por faltar cualquier antecedente histórico o regulación que posibilite una decisión sobre tales cuestiones, razón suficiente para la desestimación del recurso." 14

13 Sobre este tema véase LEGUINA VILLA, «La responsabilidad patrimonial de la Administración, de sus autoridades y del personal a su servicio», en La nueva Ley de Régimen Jurídico de las Administraciones Públicas y del Procedimiento Administrativo Común, p. 413. Tecnos, Madrid 1993. En este mismo sentido GARCÍA DE ENTERRÍA, E. La responsabilidad patrimonial del Estado legislador en el Derecho español, p.69, editorial Civitas, segunda edición 2007. y Manual de Responsabilidad Pública, Abogacía General del Estado, p. 476, Dirección del Servicio Jurídico del Estado, edición Ministerio de Justicia, 2004.

14 Tribunal Supremo, STS 1992/8679 de noviembre 30, reiterada en la STS 1993/1069. Sobre esta sentencia García De Enterría expresa "La Sentencia me parece excelentemente motivada, opinión que veremos no comparte toda la doctrina. Comienza rechazando que del art. 9.3. de la Constitución se derive directamente una responsabilidad del Legislador en nuestro Derecho, ante la falta de un desarrollo legislativo del principio abstracto, como ha ocurrido en el caso de la responsabilidad de la Administración (en desarrollo del art. 106.1 de la Constitución) y de la actuación de los órganos judiciales (en desarrollo del art. 121). En todo caso, no resulta posible la aplicación analógica del régimen de responsabilidad de la administración, pues todas las normas que lo rigen se refieren al $<<$ funcionamiento de los servicios públicos $>>$, concepto en el que no es posible subsumir al legislador.” GARCÍA DE ENTERRÍA, E. Op. Cit., pp. 69 y 70. 
Por su parte para otro sector doctrinal ${ }^{15}$ el contenido del art. 9.3 C.E.

"3. La Constitución garantiza el principio de legalidad, la jerarquía normativa, la publicidad de las normas, la irretroactividad de las disposiciones sancionadoras no favorables o restrictivas de derechos individuales, la seguridad jurídica, la responsabilidad y la interdicción de la arbitrariedad de los poderes públicos",

es suficiente para que sea posible establecer responsabilidad patrimonial en la actividad legislativa.

Sobre este aspecto puede observarse lo señalado por el Tribunal Constitucional en la STC de 13 de febrero de 1997 -RTC 1997/28 F.J. 7-, en la cual esa corporación al resolver una cuestión previa de constitucionalidad sobre la ley 1/1984 del Parlamento de las Islas Baleares, manifestó:

"Es claro que el silencio de la ley sobre este particular no puede ser considerado como una exclusión vulneradora de lo dispuesto en el art. 33.3. C.E, sino que ha de entenderse que ese extremo quedará sometido a la normativa general del ordenamiento jurídico sobre la responsabilidad patrimonial por actos de los poderes públicos que procede otorgar a quienes, por causa de interés general, resulten perjudicados en sus bienes y derechos."

En este mismo sentido se pronuncia el Tribunal Supremo en la STS de 14 de febrero de 2002

"La responsabilidad patrimonial del legislador está efectivamente contemplada en el artículo 9.3 de la Constitución y en el artículo 139.3 de la ley 30/1992 (RCL 1992, 2512, 2775 y RCL 1993, 246), que se remite a lo que se establezca en los propios actos legislativos. La Sala Tercera del Tribunal Supremo, sentencia de 30 de noviembre de 1992 (RJ 1992, 10516), había establecido ya una doctrina coincidente con el sistema adoptado por el legislador en la citada ley 30/1992, de manera que, salvo en los supuestos de leyes de naturaleza expropiatoria, en que siempre habrá derecho a la correspondiente indemnización, en los demás habrá que estar a lo que establezcan las propias leyes." ${ }^{16}$

Si bien es cierto que la C.E. no señala en forma específica la responsabilidad del Estado por la actividad del legislador, no se puede desconocer que el art. 9.3. C.E. a pesar de su carácter general, sí lo hace, de lo contrario se permitiría que

15 GALÁN VIOQUE, R. De la Teoría a la Realidad de la Responsabilidad del Estado Legislador, en revista de administración pública, p. 288, No. 155, 2001. En este mismo sentido LÓPEZ MENUDO, F., La responsabilidad patrimonial de los poderes públicos, p. 322, editorial Lex Nova, 2005. y GARRIDO FALLA y FERNÁNDEZ PASTRANA. Régimen Jurídico y procedimiento de las administraciones públicas, p. 398. $3^{\text {a }}$ edición, Editorial Civitas, 2000.

16 Tribunal Supremo, Sección 6 ${ }^{\mathrm{a}}$, STS RJ 2002/1678, F.J. $1^{\circ}$. 
uno de los poderes públicos del Estado, pueda actuar sin limitaciones ${ }^{17}$. Ahora bien, aun cuando el Tribunal Supremo no se pronuncie en forma clara sobre este tema, parece que, si bien formalmente no reconoce al art. 9.3 C.E. como fundamento de la responsabilidad, en forma material si lo ha hecho, toda vez que ha reconocido la responsabilidad patrimonial del Estado legislador. ${ }^{18}$

La presencia de la voluntad del legislador en el reconocimiento de la responsabilidad, es decir que la propia ley que irroga el posible daño deba expresar la aceptación de esa carga reprochable al legislador, ha sido alegada por algún sector de la doctrina ${ }^{19}$ como uno de los requisitos para que proceda la declaración del juez en ese sentido, de no ser así el poder judicial estaría irrespetaría el principio de separación de poderes, tal postura fue adoptada por la ley 30 de 1992 en su artículo 139.3, el cual dispone que Principios de la responsabilidad. ...3. Las Administraciones Públicas indemnizarán a los particulares por la aplicación de actos legislativos de naturaleza no expropiatoria de derechos y que éstos no tengan el deber jurídico de soportar, cuando así se establezcan en los propios actos legislativos y en los términos que especifiquen dichos actos. ${ }^{20}$

Con relación a este aspecto ha de precisarse que, en este trabajo, se hace un análisis de la responsabilidad patrimonial del Estado legislador cuando es el propio acto legislativo el que puede llegar a ocasionar el perjuicio, por el contrario, el supuesto regulado por el art. 139.3 se refiere a actos administrativos -que son los que pueden llegar a generar el perjuicio- que apliquen actos legislativos, lo anterior

17 Por esta razón se comparte la afirmación de Galán Vioque cuando expresa "La posterior instauración de jurisdicciones constitucionales con capacidad para controlar la validez de las leyes desmontaría por completo la falsa idea de la infiscabilidad de la actividad legislativa, dejando inservibles las posiciones doctrinales que pretendian ligar soberanía con irresponsabilidad”. GALÁN VIOQUE, Op. Cit. p. 286.

18 En este sentido se comparte la afirmación de LÓPEZ MENUDO "Ahora bien, resulta un tanto desconcertante que el Tribunal Supremo siga manteniendo que $<<$ del principio general de responsabilidad de los poderes públicos del artículo 9.3 de la CE no cabe construir pretorianamente un régimen de responsabilidad del legislador $>>$, cuando asi lo hace efectivamente". LÓPEZ MENUDO, F., Op. Cit., p. 321. Por su parte Castillo Blanco afirma "Por tanto, de dichas declaraciones jurisprudenciales parece subyacer que la solución tradicional no parece convencer a nadie, ni siquiera a los tribunales que finalmente la adoptan, aunque, eso sí, más bien parece a regañadientes. No puede afirmarse sin más la existencia de una impunidad absoluta del poder legislativo." CASTILLO BLANCO, F. Op. Cit., p. 343.

19 GARCÍA DE ENTERRÍA, E. Op. Cit., p. 17.

20 En este sentido se ha pronunciado el Tribunal Supremo en la STS 1997/9424 de 19 de Diciembre. Sobre la interpretación de esta norma vale la pena observar lo dicho por Parejo Alfonso en el prólogo de Luciano Parejo Alfonso sobre la obra de Federico Castillo Blanco, para quién antes que otorgarse en forma discrecional al legislador el reconocimiento de la responsabilidad, dicha norma radica un deber de valorar las consecuencias de sus decisiones -valoración del impacto de la medida legislativa-. Cfr. CASTILLO BLANCO, F. Op. Cit., pp. 21 y 22. 
sin desconocer el avance considerable que en materia de responsabilidad implicó la expedición de la norma en comento.

\title{
1.2. El rango constitucional del Principio de Confianza Legítima
}

La responsabilidad del Estado legislador por el desconocimiento del principio de confianza legítima, va a depender de la Jerarquía que tenga en el ordenamiento jurídico dicho principio, la cual necesariamente habrá de ser constitucional, de no ser así difícilmente se podrá reprochar la responsabilidad. Sobre este tema García de Enterría considera que el principio de seguridad Jurídica art. 9.3. C.E., es el que fundamenta el principio de confianza legítima, convirtiéndose este último en una manifestación del primero, sin embargo, por tal relación no es posible asignarle al segundo el mismo rango constitucional de la cual goza la seguridad jurídica ${ }^{21}$.

Para Parejo Alfonso ${ }^{22}$, la confianza legítima si goza de carácter constitucional, en virtud de los principios de seguridad jurídica y el de Estado de Derecho. El Tribunal Constitucional resalta también el carácter constitucional del principio de confianza como derivación del principio previsto en el art. 9.3.

\begin{abstract}
"La seguridad jurídica, según constante doctrina de este Tribunal, es «suma de certeza y legalidad, jerarquía y publicidad normativa, irretroactividad de lo no favorable e interdicción de la arbitrariedad, sin perjuicio del valor que por sí mismo tiene aquel principio») (SSTC 27/1981, 99/1987 [RTC 1987|99], 227/1988 [ RTC 1988|227] y 150/1990). Y aun cuando resulta claro, como se advertía en el fundamento jurídico 8. de la STC 150/1990, que no puede erigirse en valor absoluto, pues ello daría lugar a la congelación o petrificación del ordenamiento jurídico existente (SSTC 6/1983, 99/1987 y 126/1987), consecuencia contraria a la concepción que fluye del propio art. 9.3 CE, ni debe entenderse tampoco como un derecho de los ciudadanos al mantenimiento de un determinado régimen fiscal (SSTC 27/1981 y 6/1983), «sí protege, en cambio, la confianza de los ciudadanos, que ajustan su conducta económica a la legislación vigente, frente a cambios normativos que no sean razonablemente previsibles, ya que la retroactividad posible de las normas tributarias no puede trascender la interdicción de la arbitrariedad》 (SSTC 150/1990 y 197/1992). ${ }^{23}$
\end{abstract}

Así las cosas, el principio de confianza legítima proviene del principio de seguridad jurídica art. 9.3., y se impregna de su connotación constitucional, toda

21 Cfr. GARCÍA DE ENTERRÍA, E. Op. Cit., pp. 34 y 35.

22 Cfr. CASTILlO BLANCO, F. Op. Cit., pp. 17. En este mismo sentido se expresa Castillo Blanco "Vemos, pues, cómo el propio Tribunal Constitucional respalda constitucionalmente el principio de confianza Legítima realizando una novedosa aportación a la ya importante jurisprudencial del-sic-este Tribunal sobre la seguridad jurídica, y su equilibrio en relación al principio de legalidad." En esta misma obra, p. 356.

23 Tribunal Constitucional STC 173/1996 F.J. 3. Sentencia de 31 de Octubre de 1996. 
vez que la confianza legítima en su aplicación es una manifestación especial de la seguridad jurídica.

\section{El Principio de confianza como soporte de la responsabilidad del estado legislador}

Una vez justificados el carácter constitucional del deber de responsabilidad el Estado legislador por su actividad, así como también la naturaleza constitucional del principio de confianza legítima, se dirigirá este estudio a examinar los elementos específicos que desde la aplicación del principio enunciado pueden dar origen al reconocimiento de la responsabilidad patrimonial.

\subsection{La innovación o la petrificación del ordenamiento jurídico en la aplicación del principio de confianza legítima}

La expedición de una ley puede traer consigo la modificación de una situación jurídica específica, pues el objeto de las normas se endereza a producir efectos jurídicos frente a una determinada situación. El análisis de esa potestad del Estado legislador de configurar libremente su ordenamiento jurídico, de innovarlo, frente al deber de respeto del principio de confianza, plantea un problema jurídico, que debe ser abordado en este punto.

La cuestión jurídica que se genera, es si el interés general que está inmerso en la elaboración de una ley ha de ser frenado o petrificado por el interés de los particulares que puedan verse afectados por la norma, es decir, si una minoría debe soportar una situación que le ocasiona perjuicios, a favor de los beneficios que le pueda reportar a la mayoría.

Frente a este tema se encuentra posiciones que abogan por la libertad de configuración del legislador ${ }^{24} \mathrm{y}$, por ende, la no aplicación de la confianza legítima como fundamento de la responsabilidad. Y otra posición consistente en que si bien

24 Considera García de Enterría sobre este punto "Ésa es, más bien, y precisamente, la concepción del Derecho del Antiguo Régimen, más que la de la democracia moderna, la que subyace a la idea de que cualquier cambio legislativo que afecte la confianza que en el Derecho anterior tuviesen los ciudadanos o grupos de ellos pueda generar a favor de los mismos una pretensión indemnizatoria, lo que conduciria inevitablemente, como ha dicho tanto el Tribunal Constitucional, como el Tribunal Supremo, a una petrificación o congelación del derecho, a su inmovilización total o parcial, a su cierre definitivo a los cambios sociales o políticos, que es una de las grandes funciones de un poder legislativo democrático, señor indiscutido de la legis innovatio. GARCÍA DE ENTERRÍA, E. Op. Cit., pp. 42 y 43 . 
el legislador puede innovar en el ejercicio de su actividad, el Estado debe responder por los posibles perjuicios que pueda ocasionar ${ }^{25}$.

Es precisamente esta segunda postura la que ha utilizado el Tribunal Supremo, para lo cual valora los intereses generales en juego frente al interés del particular que es lesionado, como ejemplo puede citarse el caso de la eliminación de cupos exentos que habían sido concedidos como medidas de fomento a las empresas pesqueras y que perjudicaban sus inversiones -interés particular, situación en la cual confiaban-, como consecuencia de la aprobación de la ley orgánica que autorizaba la Adhesión de España a las Comunidades Europeas -interés general-, por tal motivo, el Tribunal Supremo decidió indemnizar a los empresarios, debido al sacrificio de derechos o al menos intereses patrimoniales, que no debían soportar ${ }^{26}$.

El legislador se encuentra facultado para modificar la ley, sin embargo, tal posibilidad de innovación no puede ir en contravía del principio de confianza legítima, y en el evento de hacerlo, el Estado se encuentra obligado a responder por los intereses de los particulares afectados, aún cuando su actuar se dirija a satisfacer un interés general.

\subsection{La ausencia de previsión y medidas transitorias en la expedición de las leyes}

Como ya se mencionó en el acápite anterior el legislador puede innovar la ley y modificarla. Sin embargo el principio de confianza legítima, exige que en el ejercicio de esa actividad se observe el deber de previsión de los efectos que la norma puede producir -daños a particulares-, y en el evento que pueda ocasionar perjuicios adopten las medidas transitorias que compensen o, por lo menos, minimicen ese daño, de lo contrario se puede llegar a configurar la responsabilidad patrimonial del Estado legislador.

25 En este sentido González Pérez participa de este enfoque cuando señala "Pero, además, es que en modo alguno se pone en tela de juicio la potestad de que el legislador cambie la ley. Lo que se afirma es que si el cambio legislativo -como del funcionamiento normal de la Administración- se producen perjuicios cuantificables económicamente a quien actuó en la confianza que le daban ciertos actos de la Administración realizando unas importantes inversiones, el Estado, que es uno (legislador, administrador y juez), indemnice los perjuicios que derivan directamente del cambio". GONZÁLEZ PÉREZ, J. Op. Cit., p. 61.

26 La sentencia que se comenta es la STS de 5 de marzo de 1993. Sobre este tema particular Vaquer Caballería considera "Todo ello no puede hacer olvidar, sino que debe combinarse a su vez con la serenidad que requiere la determinación del interés general (que pasa por ponderar con objetividad los diversos intereses afectados, públicos y privados) y la preservación del valor de estabilidad que es así mismo consustancial a todo orden jurídico. No en vano el principio jurídicoadministrativo de la confianza legítima, por ejemplo, ha sido construido como un corolario del de seguridad jurídica, en su dimensión de "Derecho Previsible", como se verá más adelante." VAQUER CABALLERíA, M. Op. Cit., p. 2. 


\section{Castillo Blanco manifiesta al respecto}

"De todo lo dicho, es preciso hacer ya una proposición que no puede consistir sino en que el alcance y contenido del principio de seguridad jurídica, tal y como lo recoge nuestra Constitución, alcanza, en su vertiente de confianza legítima, ciertos deberes positivos de actuación de los poderes públicos $\mathrm{y}$, en especial, del poder legislativo que ha de prever -no con carácter potestativo, pues la seguridad jurídica no es un principio constitucional de tal carácter, sino que al contrario, es de obligatoria observancia- el establecimiento de situaciones transitorias y medidas que restauren la situación de aquellos individuos $\mathrm{u}$ organizaciones que legítimamente podían confiar en su mantenimiento."27

El Tribunal Supremo ha destacado este aspecto en las sentencias correspondientes a los agentes aduanas ${ }^{28}$, en los cuales se denegó la protección de la confianza legítima por cuanto que la medida legislativa previó los posibles perjuicios - de los particulares en el desempeño de su labor- y contempló una serie de medidas transitorias.

\subsection{Los bienes, derechos o intereses que protege el principio de la confianza legítima}

Resulta importante establecer cuáles son los bienes, derechos o intereses que protege el principio de confianza legítima, para precisar el daño producto de la medida legislativa, así mismo para determinar si debe alegarse la vulneración del principio de confianza, o si debe hacerse uso del supuesto previsto en art. 33.3 C.E.

De acuerdo al campo de aplicación del principio, se puede afirmar que el objeto de protección de la confianza son las expectativas legítimas ${ }^{29}$, así lo ha señalado el Tribunal Supremo

"Razones todas las cuales determinan a esta Sala a estimar que no es aplicable a este supuesto el principio general de protección a la confianza legítima,

27 CASTILlO BLANCO, F. Op. Cit., p. 359. En este mismo sentido, VAQUER CABALLERÍA, M. Op. Cit.. p. 13. Así mismo, CONCHEIRO DEL RÍO, J. Responsabilidad patrimonial del Estado por la declaración de inconstitucionalidad de las leyes: su posible reclamación con carácter retroactivo según el Tribunal Supremo, p. 378, Ediciones Dijusa, 2001. y LÓPEZ MENUDO, F., Op. Cit., p. 329

28 Entre otras las STS 1997/4632, 1999/6544 y 1999/7475.

29 Para Viana Cleves por expectativas legítimas debe entenderse "Las expectativas legítimas son aquellas esperanzas que surgen a favor de un particular y que se fundamentan en "signos externos" o "en bases objetivas", lo "suficientemente concluyentes para que orienten al ciudadano hacia una determinada conducta" y para que cualquier "observador externo pueda reconocerlas y calibrar su dimensión objetivable". Suponen "un impacto real y efectivo, no previsible" y "especialmente dañino". Las expectativas legítimas, a pesar de no ser parte del patrimonio de un individuo, tienen certeza de configuración futura. VIANA CLEVES, M.J. El principio de Confianza Legítima en el derecho administrativo colombiano. P. 210. Ediciones Universidad Externado de Colombia, 2007. 
cuyo corolario pueda concretase en la resarcibilidad por frustración de expectativas legítimas, que aqui por las razones invocadas no existen ya que no pueden calificarse como tales las simples esperanzas o eventualidades indeterminadas carentes de trascendencia jurídica." 30

Los derechos adquiridos y bienes no entran en el ámbito de protección de la confianza legítima, toda vez que ante la existencia de una medida legislativa que irrespete los mismos, entra en juego la aplicación del supuesto previsto en el art. 33.3 C.E., es decir la expropiación.

En este orden de ideas se puede concluir que al expedirse una medida legislativa imprevista, que no contiene un régimen transitorio o, por lo menos, compensatorio y se lesionan las expectativas legítimas de los particulares, el Estado deber ser llamado a responder patrimonialmente por la violación del principio constitucional de confianza legítima.

\section{4. ¿Cómo se reparan los perjuicios ocasionados por el desconocimiento del principio de confianza legítima?}

Una vez se verifica la configuración de la responsabilidad patrimonial del Estado por su actividad legislativa, para llevar a cabo la reparación de los perjuicios debe tenerse en cuenta que el principio de protección de la confianza legítima plantea -como se dijo en la parte introductoria de este trabajo- un conflicto entre seguridad jurídica y legalidad, entre expectativas legítimas o intereses del particular y el interés general.

De acuerdo con lo anterior, se considera que le corresponde al Juez ponderar los intereses que se enfrentan, para determinar la medida indemnizatoria ${ }^{31}$ que ha de adoptar, la cual puede ser: a) la invalidación de la norma en este supuesto deberá plantear la cuestión de inconstitucionalidad ${ }^{32}, o$ b) reparar los perjuicios causados a los intereses patrimoniales. Para algunos autores ${ }^{33}$ la reparación debe realizarse solo vía indemnización, de esta forma no se ocasionaría la petrificación del ordenamiento jurídico, esta última es la vía que ha tomado el Tribunal Supremo ${ }^{34}$.

30 T.S. Sección $6^{\text {a }}$, STS 1995/9061 de 5 de diciembre.

31 Medina Alcoz señala sobre el particular que para establecer la indemnización por vulneración de la confianza se deben seguir las reglas de la responsabilidad precontractual. Cfr. MEDINA ALCOZ, L. Confianza Legitima y Responsabilidad Patrimonial, en Civitas Revista española de derecho administrativo, p. 299, $\mathrm{n}^{\circ} 130$ (2006).

32 En el caso de la ley $1^{\text {a }}$ de 1984 de Baleares en la cual el Tribunal Supremo reconoció responsabilidad patrimonial del legislador-autonómico- STS 1998/1677 de 17 de Febrero, el T.S. planteó la cuestión previa de inconstitucionalidad que fue resuelta por el T.C. en la S.T.C. No. 28/1997-RTC 28/997de 13 de febrero.

33 ALONSO GARCÍA, M.C. La responsabilidad Patrimonial del Estado Legislador, p. 111, Ediciones Marcial Pons, 1999. En este mismo sentido CONCHEIRO DEL RÍO, J. Op. Cit., p. 369. Y MEDINA ALCOZ, L. Op. Cit. p. 325.

34 Por este camino ha optado el TS en la STS 1998/1677 y en la STS de 5 de marzo de 1993 comentada en este trabajo. 


\section{La competencia del juez contencioso administrativo para declarar la responsabilidad patrimonial del Estado legislador, en el supuesto del desconocimiento del principio de confianza legítima}

La competencia del Juez Contencioso para declarar la responsabilidad patrimonial del Estado por violar la confianza legítima, ha sido cuestionada por García de Enterría quien si bien no le reconoce rango constitucional al principio, considera que en caso de tenerlo es necesario que el juez contencioso administrativo proponga la cuestión de inconstitucionalidad, sin que sea posible que el juez ordinario pueda reconocer directamente la responsabilidad ${ }^{35}$.

No se comparte esa aseveración, porque la misma parte del supuesto de la declaratoria de inconstitucionalidad de la ley para que sea viable el reconocimiento de la responsabilidad patrimonial, por violación de la protección de la confianza, no obstante que, como se ha visto en los casos de las empresas pesqueras eliminación de cupos exentos- y en el de la ley Balear 1/1984 -urbanizaciones-, es viable que se reconozca la responsabilidad sin acudir a la declaratoria de inconstitucionalidad de la norma, más aún cuando en este segundo caso se planteó la cuestión de inconstitucionalidad y fue resuelta en forma desfavorable por el Tribunal Constitucional, y aún así se declaró la responsabilidad patrimonial por el Tribunal Supremo.

\section{CONCLUSIONES}

- El fundamento de la responsabilidad patrimonial del Estado por el ejercicio de su actividad legislativa se encuentra en el art. 9.3. C.E, el cual contiene el principio de responsabilidad de los poderes públicos y, por lo tanto, del poder legislativo.

- El principio de confianza encuentra su fundamento en el principio de seguridad jurídica art. 9.3. C.E., y como una manifestación especial de este último conserva su rasgo constitucional.

- La facultad de modificación o innovación legislativa de la cual se encuentra revestido el legislador, encuentra una limitación en el principio de confianza legítima, por tal motivo, debe respetar sus postulados, en caso de no hacerlo, surge en el Estado el deber de responder por los intereses de los particulares que puedan verse afectados, aún cuando su actuar se dirija a satisfacer un

35 Cfr. GARCÍA DE ENTERRÍA, E. Op. Cit., p. 45. Por su parte Alonso García, Considera que la competencia sería del Tribunal Constitucional, toda vez que para ella el fundamento de la responsabilidad patrimonial del Estado legislador radica en el desconocimiento del art. 14 C.E. ALONSO GARCÍA, M.C. Op. Cit.. pp. 103 y 104. 
interés general.

- En el ejercicio de la actividad legislativa, y en virtud del principio de confianza legítima el legislador debe prever los efectos jurídicos que la norma puede producir - daños a particulares-, y si encuentra que la ley puede ocasionar perjuicios, debe adoptar las medidas transitorias que compensen o por lo menos minimicen ese daño, de lo contrario se puede llegar a configurar la responsabilidad patrimonial del Estado legislador.

- El principio de protección de la confianza protege expectativas legítimas e intereses patrimoniales, no protege derechos adquiridos.

- La responsabilidad patrimonial del Estado por el ejercicio de su actividad legislativa se configura si lesiona expectativas legítimas o intereses patrimoniales de los particulares, como consecuencia de la falta de previsión de los posibles efectos de la norma, o que habiéndolos previsto no fijó unas medidas transitorias que permitieran compensar o minimizar el daño. Estructurándose de esta forma el desconocimiento del principio de confianza legítima.

- Los perjuicios ocasionados por el desconocimiento del principio de confianza legítima por la actividad legislativa se pueden reparar de dos formas: primero al invalidar la norma en este supuesto deberá plantear la cuestión de inconstitucionalidad, y segundo, reparar los perjuicios causados a las expectativas legítimas o intereses patrimoniales, este supuesto ha sido utilizado por el Tribunal Supremo.

- El Juez Contencioso Administrativo se encuentra facultado para reconocer la responsabilidad patrimonial del Estado legislador por el desconocimiento del principio de confianza legítima.

\section{REFERENCIAS}

Alonso, M.C. (1999). La responsabilidad Patrimonial del Estado Legislador, ediciones Marcial Pons.

Botero, L.F. (2007). Responsabilidad Patrimonial del legislador, Editorial Legis.

Castillo, F. (1998). La protección de confianza en el derecho administrativo, editorial Marcial Pons.

Concheiro Del Río, J. (2001). Responsabilidad patrimonial del Estado por la declaración de inconstitucionalidad de las leyes: su posible reclamación con carácter retroactivo según el Tribunal Supremo, ediciones Dijusa,

Galán, R. (2001). De la Teoría a la Realidad de la Responsabilidad del Estado Legislador, en revista de administración pública, $\mathrm{N}^{\mathrm{o}} 155$,

García De Enterría, E. (2007). La responsabilidad patrimonial del Estado legislador en el Derecho español, Editorial Civitas, segunda edición. 
García, J. (2002). El Principio de Protección de la Confianza en el Derecho Administrativo, editorial Civitas,

García, R. Contenido y Límites del Principio de Confianza Legítima: Estudio Sistemático en la Jurisprudencia del Tribunal de Justicia, en: Revista española de derecho administrativo.

Garrido Falla y Fernández Pastrana. (2000). Régimen Jurídico y procedimiento de las administraciones públicas, $3^{\text {a }}$ edición, Editorial Civitas.

González, J. y Otros. (1999). Comentarios a la ley 4/1999, de 13 de enero, de modificación de la ley 30 de 1992, editorial Civitas,

Leguina, J. (1993). La responsabilidad patrimonial de la Administración, de sus autoridades y del personal a su servicio, en La nueva Ley de Régimen Jurídico de las Administraciones Públicas y del Procedimiento Administrativo Común, Tecnos, Madrid

López, F. (2005). La responsabilidad patrimonial de los poderes públicos, editorial lex nova.

Lorenzo De Membiela, J.B. (2006). El Principio de Confianza Legítima como Criterio Ponderativo de la Actualidad Discrecional de la Administración Pública, en Revista de Administración Pública Nº 171.

Manual de Responsabilidad Pública, Abogacía General del Estado, Dirección del Servicio Jurídico del Estado, edición Ministerio de Justicia, 2004.

Medina, L. (2006). Confianza Legítima y Responsabilidad Patrimonial, en Civitas Revista española de derecho administrativo, $\mathrm{n}^{\mathrm{o}} 130$.

Sanz I. (2000). El Principio de Confianza Legítima, Limitador del Poder Normativo Comunitario, en Revista de Derecho Comunitario Europeo No. 7, enerojunio de 2000.

Vaquer, M. La aplicación del ordenamiento jurídico en el espacio y el tiempo. Universidad Carlos III de Madrid.

Viana, M.J. (2007). El principio de Confianza Legítima en el derecho administrativo colombiano, ediciones Universidad Externado de Colombia. 